\title{
INTRODUCTION TO SCIENCE: A CURRICULUM APPROACH
}

\section{André A. G. Bianco, Bayardo B. Torres.}

Biochemistry Departament, Chemistry Institute, Sao Paulo University, Sao Paulo, Brazil.

International and national institutions concerned with higher education recommend the inclusion in curriculum of strategies to promote development of aditional skills then traditionals memorazing habilities and contents reproduction. Between this, special attention is given to stimulating the critical capacitie. To develop this skills, was given a project, included into the Biochemistry discipline, with freshmen students in the Nutrition course of the Saúde Pública College of USP. The project consisted into the scientific articles analysis and in the elaboration of research projects at the Scientific Initiation level. The first part presented the way how Science is divulged and the second, the mold that the scientific knowledge is generated. All activities was always conducted by active communication strategy. The general goal was bring near the students of scientific proceedings, contribute to developed scientific attitude, that is to say, critical sense. The proceeding was evaluated by quantitative methods (questionnaire) and qualitative (interview with differents participant) and the results point for a significative increase of knowledge of scientific job and a developed of yerned skills.

Key words: Scientific formation, scientific articles, scientific method.

Thanks: CAPES and CNPq. 